\title{
Job for Jakarta
}

\section{Indonesia's incoming government must act decisively to protect the nation's forests.}

Whatever the outcome of the Indonesian presidential election this July, political bickering and wrangling is set to continue. This could spell disaster for the nation's wondrous natural wildernesses.

Located between the Pacific and Indian oceans and straddling the boundary of the Oriental and Australian faunal regions (as drawn by British naturalist Alfred Russel Wallace in 1859), Indonesia - the world's largest archipelago - is a biodiversity hotspot. Its diverse lowland, montane and riparian tropical forest habitats support unique assemblages of plants, mammals, reptiles, amphibians, fish and birds, not to mention an inordinate number of insects and other invertebrates, many of which remain to be scientifically described and categorized. One iconic taxon is the parasitic plant Rafflesia arnoldii, which produces the largest known flower (called the corpse flower due to its repulsive odour). Others include the Sumatran orangutan (Pongo abelii) and the critically endangered Javan rhinoceros (Rhinoceros sondaicus). Within the lowland forests many species of epiphytic (that is, deriving sustenance from the air and rain) orchids and vines are also found, as well as lianas - soil-rooted woody plants that use huge buttressed trees as vertical supports to climb up to the sunlit canopy.

Unfortunately, the forests of Indonesia also contain many commercially important trees, including valuable hardwoods. Despite an official 'moratorium' on deforestation implemented in 2011, logging and landconversion for oil palm plantations and other economically 'high value' uses continues unabated. To some extent this is understandable; with over 250 million inhabitants, Indonesia is the fourth most populous country in the world. Although a member of the G20 group of major economies, the nation has high levels of poverty and the over-exploitation of natural resources is a tempting quick fix. But in the long term, such a strategy is patently unsustainable.

The clearing of Indonesia's lowland and wetland primary forests at an unprecedented rate is not only bad for biodiversity conservation, it also diminishes the benefits that people gain, either directly or indirectly, from intact forests. These 'ecosystem services' include the provision of fresh water, food, wood for cooking and so on. But from

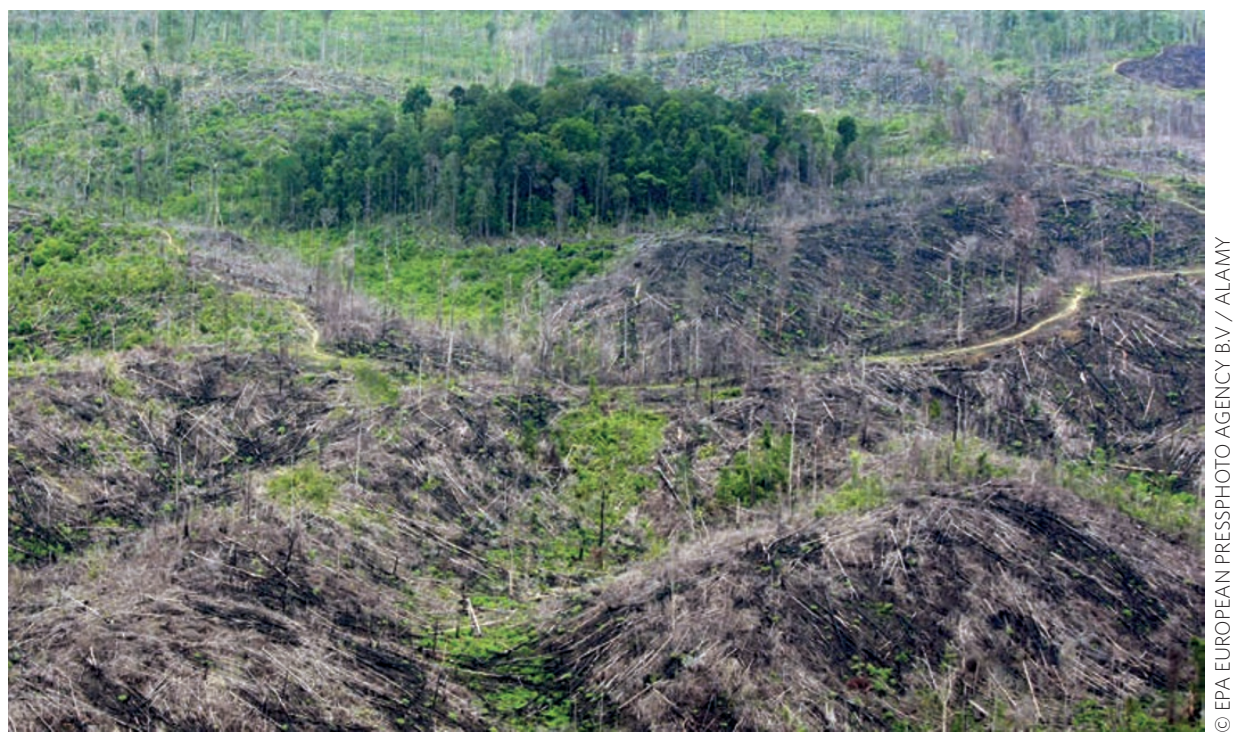

a climate change mitigation perspective there is also one major service provided by intact primary forest: carbon storage. Even if replaced with plantations, the clearance of primary forest results in significantly increased greenhouse gas emissions (especially carbon dioxide), of which Indonesia is, according to the World Bank, already the third largest emitter globally (http://go.nature.com/BLNZip).

And yet despite the importance of the issue, there has been no consensus on the areal extent of primary forest loss in Indonesia, or indeed on the rates of loss and their spatial and temporal trends. Similarly, the primary drivers of forest clearance in Indonesia are poorly understood. In a timely reminder of this sorry state of affairs, Belinda Margono and colleagues (page 730) report that tropical deforestation in Indonesia is now outpacing that of Brazil. They show that over the period 2000-2012, Indonesia lost around 6 million hectares of primary forest, and that the rate of deforestation has increased on average by 47,600 hectares per year.

Margono et al. show that logging first degrades areas of forest before the bulldozers go in for wholesale forest clearance and land conversion. It seems that lowland and wetland forests are especially vulnerable, which is particularly undesirable - peatlands, for example, store vast amounts of carbon, which is released on burning. Significant losses are occurring even in areas where deforestation is officially restricted or prohibited. Margono et al. note, for example, that nearly half of montane primary forest loss occurred within 'protected' areas. Forest degradation and clearance generates a vicious cycle: road construction and wetland drainage allows easier access for continued logging. The end result is the devastation of vast tracts of primary forest cover (pictured).

In addition to the problem of greenhouse gas emissions associated with deforestation and land-use change, Indonesia is highly dependent on fossil fuels for energy, which are another major source of emissions. In July, the United Nations Sustainable Development Solutions Network and the Paris-based Institute for Sustainable Development and International Relations jointly published an interim report entitled Pathways to Deep Decarbonization (http://go.nature.com/BEGvkl). The chapter on Indonesia outlines ways that the nation can achieve significant decarbonization of its economy.

Indonesia has people of many ethnicities, languages and creeds. By protecting its primary forests, and fostering renewable sources of energy, the nation could better live up to its motto - Bhinneka Tunggal Ika (unity in diversity) — and make a major contribution to climate change mitigation. $\square$ 